\title{
Technique for experimental studies of asphalt concrete milling process
}

\author{
Sharofiddin Pirnaev", Rakhmat Sindarov, Fotima Dzhumabeva, and Shoira Saidova \\ Tashkent State Transport University, Uzbekistan
}

\begin{abstract}
The paper considers the issues of destruction of the working bodies of road-building equipment operated under conditions of abrasive wear with a fixed abrasive. Analytical studies of the influence of the tribological parameters of cutters on the intensity of their wear have been carried out. Based on the solution of the equations of the dynamics of the movement of the cutter in a viscoelastic medium, its geometric shape is optimized. The mathematical dependences of the influence of the geometric dimensions of the cutter on the pressure value and the intensity of tool wear are obtained.
\end{abstract}

\section{Introduction}

Research questions of the theory of soil destruction of various strength by mechanical tools, which can be the cutters of the milling working bodies, are also assigned, the work such scientists V.N. Goryachkina, N.G. Dombrovsky, A.N. Zelenina, Yu.A. Vetrova, V.D. Abezgauz, K.A. Artemieva, D.I. Fedorov, IN AND. Balovnev, V.L. Baladinsky, I.A. Nedorezova, I.S. Poltavtseva, D.P. Volkova, I.P. Borodacheva et al.

The analysis showed that these works depend on the destruction of soils of different strength. They are also successfully used for the destruction of materials such as asphalt and cement concrete. These dependencies allow you to determine the impact of various factors on energy intensity and productivity of processes destruction of various materials by the working bodies of rotor milling machines to establish their optimal parameters and rational operating modes. At the same time, in domestic and foreign literature, there is no information on studies of the work of eccentric milling equipment on all types of materials.

\section{Methods}

The organization of experimental research requires the solution of generalizing methodological issues that allow one to develop the governing principles for using the results of a model experiment in practice and to provide a unified approach to conducting such experiments at all stages. The methodology of experimental research on the creation of working bodies of the road milling cutter involves the solution of the following issues [1, $3,4]$ :

*Corresponding author: sharofiddin2306@mail.ru 
1. Development of a research plan;

2. Justification and selection of linear dimensions of the working body model, experimental setup and material samples used in experiments;

3. Substantiation and selection of parameters that can be changed and controlled in the course of experimental research;

4. Design and manufacture of experimental equipment;

5. Selection of the required instrumentation.

In experimental studies, the wear resistance of the cutters and the load on the road milling cutter drive were determined. The mechanism of abrasive wear of steels and alloys is most qualitatively determined using research methods on special test benches, mainly based on turning or milling machines [4, 6-8]. These techniques make it possible to fully establish the mechanism of material wear depending on the cutting speed, the abrasiveness of asphalt concrete, the temperature in the area of contact between the cutting edge and abrasive, etc.

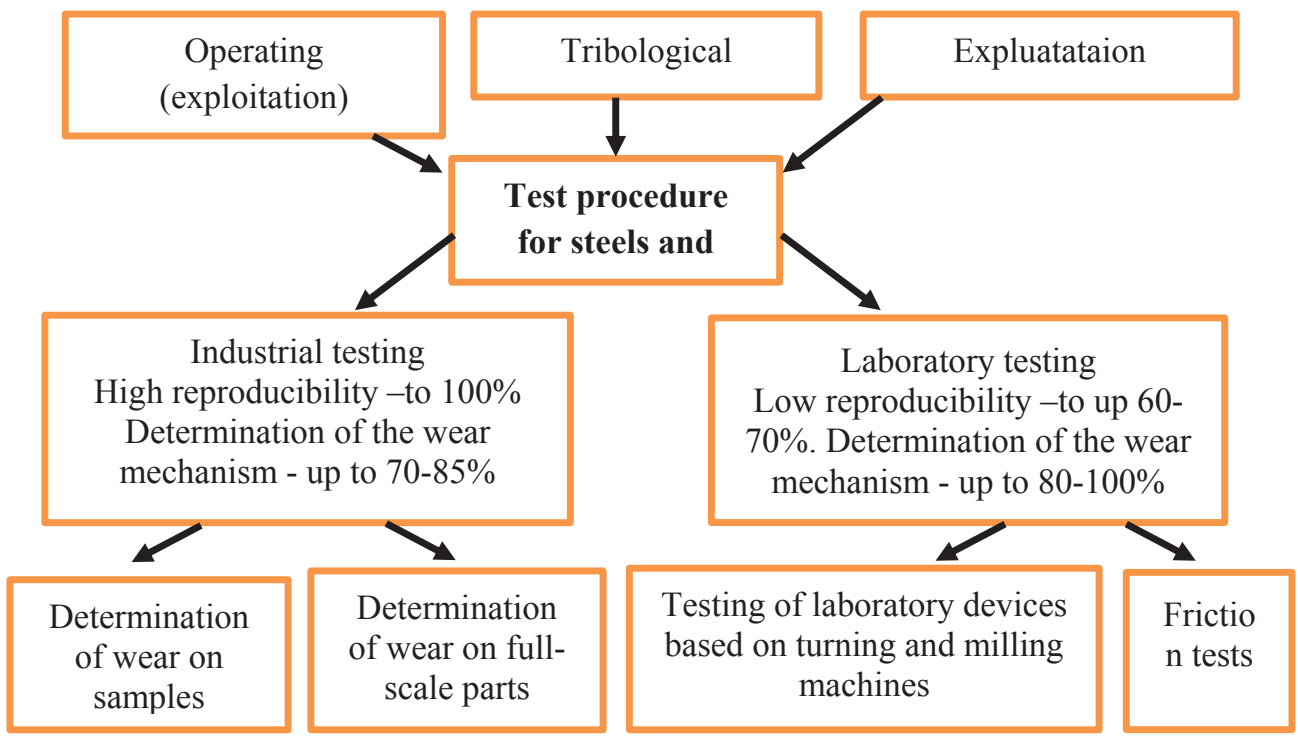

Fig. 1. Methods of testing steels and alloys in abrasive environments [9]

For a road milling cutter cutters subject to intense wear by a fixed abrasive with the presence of local shock loads, the initial operating parameters are [3]:

- cutter geometry (length L, body diameter $\mathrm{D}$, tip height $\mathrm{H}$ ),

- modes of asphalt concrete milling (the depth of the cutter drum depth into the asphalt concrete $\mathrm{P}$, the speed of rotation of the cutters $\mathrm{V}$ ),

- physical and mechanical properties of asphalt concrete (ultimate strength in uniaxial compression $\sigma_{\text {comp }}$, ultimate tensile strength $\sigma_{\mathrm{w}}$ ).

To study the process of interaction of the road milling cutter working body with asphalt concrete, it is required to find out the dependence of the average torque and power of the power plant on:

- maximum milling depth;

- translational speed of movement of the road milling cutter;

- the location of the cutters and their geometry. 


\subsection{Scheme of the experimental stand}

Experimental studies were carried out based on a physical modeling stand. The general layout of the stand is shown in figure 2 .

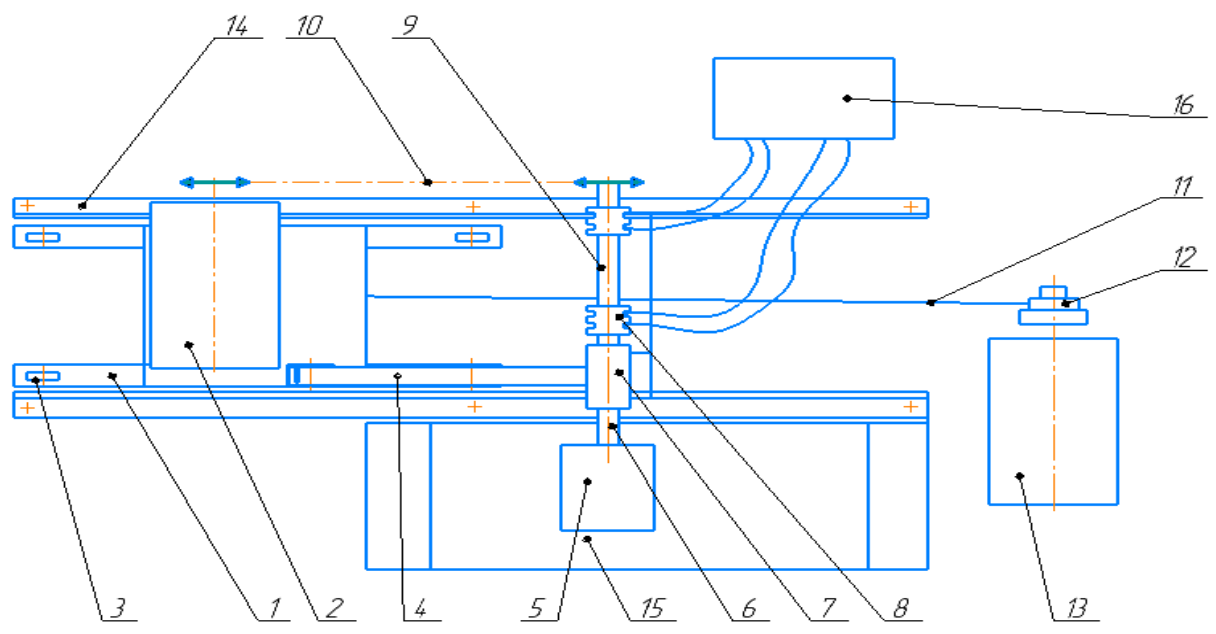

Fig. 2. Diagram of a stand for modeling the operation of a road milling cutter

The stand consists of a movable platform 1, which moves on rollers 3 along the supporting surface of the table along rigidly fixed guides 14 using an electric drive at position 13. A drum 12 with a set of cylindrical surfaces serves to change the translational speed of the movable platform. A swivel bar 4 with a bearing unit 7 is fixed on the platform, capable of changing the milling depth. The eccentrically driven cutter 5 is driven by a second electric drive at position 2 through a chain drive 10. Strain gauges 9 are glued to the shaft 6; current collectors 8 are installed, connected with the control and measuring equipment 16. The material is milled in a container rigidly fixed on the table 15 . Registration of the torque arising during the operation of the cutter was carried out using a set of strain gauge equipment.

\subsection{Technique for research of cutter wear}

At the first stage of experimental studies of the wear of the road milling cutters, a preliminary examination of the test specimen for the presence of defects was carried out, and deviations in geometric dimensions from the base shape were established (figure 3).

$$
\Delta \mathrm{D}=\mathrm{D}_{\text {Vgland }}-\mathrm{D}_{V \text { test }}, \Delta \mathrm{L}=L_{\text {Vgland }}-\mathrm{L}_{V \text { test }}, \Delta \alpha=\alpha_{\text {Vgland }}-\alpha_{V \text { test }}
$$

where $D_{V}$ is the diameter of the cutter body in the area of the tip,

$L$ is tip length,

$\alpha$ is the angle between the lateral surface and the horizontal of the cutter.

Measurement of the geometric characteristics of the tested cutter was carried out using a template and a micrometer with an accuracy of $\pm 0.01 \mathrm{~mm}$ in the height of the cutter $(H$, $\mathrm{mm})$, the height of the tip $(H H, \mathrm{~mm})$ and sections $\left(\mathrm{DH}, \mathrm{D}_{I^{-}} \mathrm{D}_{V} \mathrm{~mm}\right)$ of the cutter. The samples $(m l)$ were weighed on an analytical balance with an accuracy of $1 \cdot 10-4 \mathrm{G}$.

Its volume was measured using the " indentation method " to determine the intensity of wear of the cutter tip, its volume was measured using the "indentation method". Before and 
after testing, the geometric shape of the hard-alloy tip was fixed with a plastic mass to obtain an impression, after which the impression was filled with a colored alcohol solution of constant density. Using a tube, the volume of the impression was determined, then the mass of the tip was calculated $\left(m_{n}=\rho_{n} V_{j}\right)$. The body mass was determined by the difference between the mass of the entire cutter $(m 1)$ and the mass of the tip $\left(m_{\mathrm{n}}\right): m_{k}=m_{1}$ $-m_{\mathrm{n}}$.
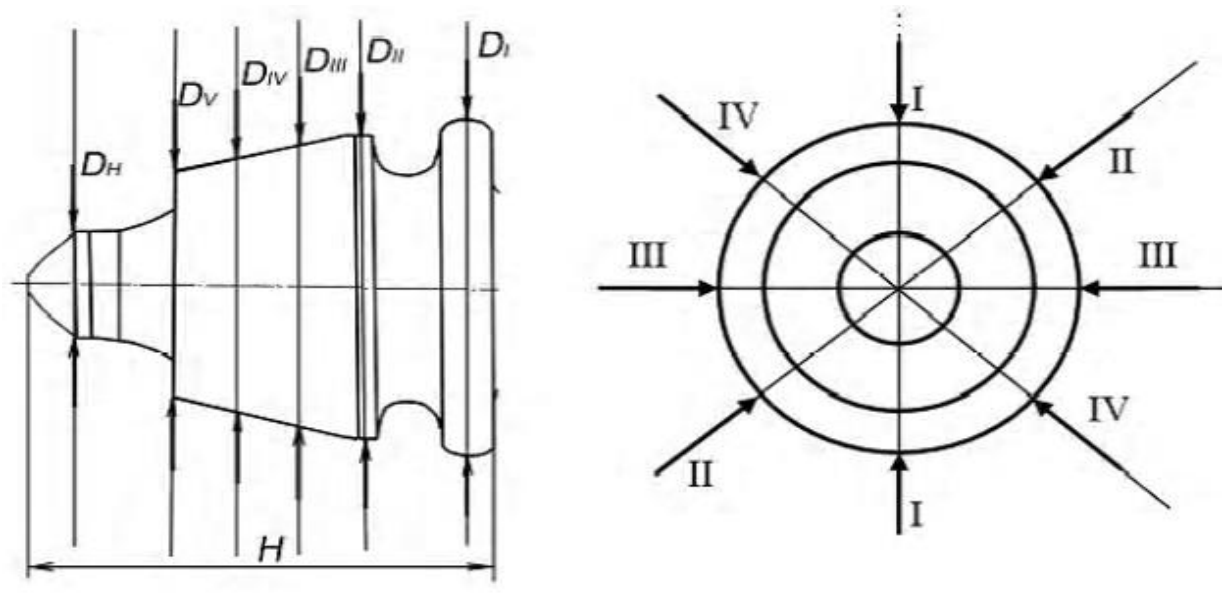

Fig. 3: Scheme of location of places for measuring the wear of cutters.

Based on this, the confidence interval of the parameters being determined is $\bar{X}=10 \%$ following [9], the number of parallel determinations $\mathrm{n}$ is determined, which is necessary to obtain, with a certain degree of confidence, based on a partial population, the average value $\bar{X}$ deviating from the average value of the total population by no more than $\varepsilon \pm 10 \%$.

In scientific research according to [10]:

$$
n=\frac{(1.960 \cdot V)^{2}}{\varepsilon^{2}}=\frac{3.84 \cdot 100}{100}=3.84 \approx 4
$$

Thus, it can be argued that to adequately determine the dynamics of wear, it is necessary to measure the wear of at least 4 cutters for given conditions.

Following GOST R 50779.21-2004 [11], we determine the maximum permissible unbiased estimate $\mathrm{S} 1$, for the standard deviation $\delta$, taking into account the number of definitions $n$ :

$$
S_{1}=M_{k} \cdot S
$$

where: $M_{k}=1.085$ is the coefficient at $n=4$.

The $\mathrm{S}$ value is determined by the formula:

$$
S=\sqrt{\frac{1}{n-1}} \sum_{i=1}^{n}\left(x_{i}-\bar{x}\right)^{2}
$$

From the definition of confidence limits for the general average with unknown general variance, it is known [11] that:

$$
\varepsilon=\frac{t_{\gamma} \cdot S}{\sqrt{n}}
$$


Student's coefficient $t_{\gamma}$ for $\gamma_{1}=\gamma_{2}=0.9$ and in case $n=4$ is equal to 1.638 . Therefore, the maximum allowable, according to formula (3), is equal to

$$
S_{1}=1.085 \frac{0,1 \bar{x} \sqrt{4}}{1,638}=0.132 \bar{x}
$$

In general, the study of cutter wear consisted of the following stages:

1. Preview and determination of the initial parameters of the cutter: height $(\mathrm{H}, \mathrm{mm})$, tip height (Hn, mm), section diameter (DH, DI-DV, MM), cutter weight (m1), cutter tip weight (mn1). Choosing a basic shape.

2. Determination of the installation site of the investigated cutter on the cutter drum.

3. Determination of external processing conditions:

ambient temperature $\mathrm{T},{ }^{\circ} \mathrm{C}$;

strength of asphalt concrete under uniaxial compression $\sigma \_$comp, MPa.

4. Installing the cutter on the cutter drum.

5. Selection of test parameters:

milling depth;

travel speed;

time of processing;

characteristics of the processed material.

6. Carrying out an experiment.

7. Removing the cutter from the drum.

8. Cleaning the tested cutter from abrasive particles, dirt, scale. Processing in an alcohol solution.

9. Determination of the parameters of the cutter after testing: height $(\mathrm{H}, \mathrm{mm})$, tip height $(\mathrm{Hn}, \mathrm{mm})$, cross-section diameter $\left(\mathrm{D}_{\mathrm{H}}, \mathrm{D}_{\mathrm{I}}-\mathrm{D}_{\mathrm{V}}, \mathrm{mm}\right)$, sample weight $\left(\mathrm{m}_{2}\right)$, cutter tip weight $\left(\mathrm{m}_{\mathrm{n} 2}\right)$.

10. Determination of cutter wear after processing an abrasive material, taking into account correction factors:

$$
\begin{aligned}
\Delta \mathrm{m} & =\left(\mathrm{m}_{2}-m_{1}\right) \cdot K \\
\Delta L & =\left(\mathrm{L}_{2}-\mathrm{L}_{1}\right) \cdot K
\end{aligned}
$$

3. Research methodology for force interaction

The experimental research program, which determines the scheme and directions of the experiments, follows from the goals of the work and should provide the solution of the set tasks by methods of physical modeling of the process of interaction of the road milling cutter tooth with asphalt concrete.

In the process of experimental studies, it was required to find out the effect on the value of the average torque and power of the power plant, the following characteristics of the process of milling asphalt concrete:

- maximum milling depth;

- translational speed of movement of the road milling cutter.

The study of the milling process is carried out in two stages.

At the first stage, the influence of the geometric parameters of the cutter on the power characteristics of the milling process is studied. This stage should ensure the ability to determine the optimal relationship between the geometric configuration of the working body and the depth of development at the lowest possible average torque.

At the second stage of experimental research, the effect of the translational speed of the base machine on the material milling process is studied. This stage allows you to evaluate various modes of milling to achieve maximum efficiency of the process.

The experimental research methodology consists of the following main stages: 
1 - selection of research objects;

2 - preparation of experimental equipment and instrumentation;

3 - study of the influence of the properties of the working environment on the milling process;

4 - preparation of abrasive material;

5 - conformity assessment of the mechanical properties of the equivalent material;

7 - setting up the experimental stand and setting the milling parameters;

8 - cutting material in a container with a cutter;

10 - control of the values that determine the milling process;

11 - visual observation, control measurements;

12 - registration of quantities that determine the milling process (average torque for one revolution of the cutter);

13 - analysis of the results obtained, conclusions by stages of research;

14 - assessment of the influence of the depth of milling on the parameters of its power plant;

15 - assessment of the effect of the forward speed of movement on the parameters of the power plant;

16 - selection of rational parameters of the process of milling by a cutter;

Parameters that can be changed during experiments include maximum milling depth; the translational speed of the moving carriage of the experimental stand.

The monitored parameters of the milling process include the value of the average torque, the nature of material destruction in the longitudinal direction.

The value of the average torque was set by the tensometric method. We used a torque meter on extensometric sensors. Load cells are placed at an angle of $\pm 45^{\circ}$ relative to the axis of the cylindrical sample (Fig. 4).

The use of a full-bridge scheme provides good linearity, better sensitivity to measured torque and compensation for parasitic effects (longitudinal tension or compression, bending).

When using sliding contacts, the effect of changing their resistance becomes negligible due to the power supply from the bridge current and the high resistance of the detector.

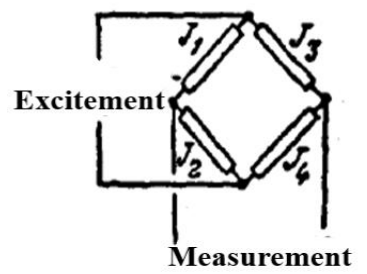

a

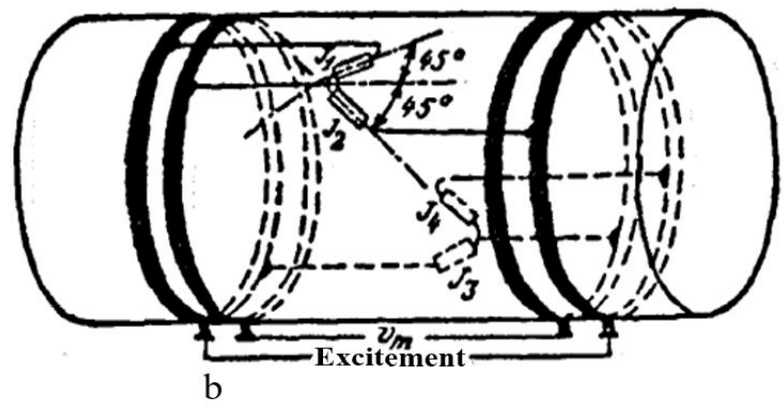

Fig. 4. The bridge of strain gauges on the cylindrical intermediate element of the torque gauge and the connection using sliding contacts: $a$ is schematic diagram; $b$ is real configuration with opposite orientation of the strain gauges.

4. Description of the equivalent material for experimental research and methods of its preparation

The method of preparing artificial materials simulating the milled asphalt concrete must ensure that the properties of the equivalent material correspond to the properties of the natural environment; relatively low cost and availability of constituent components; minimal costs and simplicity of material preparation technology; the possibility of repeated 
use of the material; stability of material properties for a long time; compliance with all environmental requirements.

In experimental studies, an equivalent material was used, consisting of sand, clay, technical oil and meeting the listed requirements. It well simulates both brittle and viscoplastic properties of strong soils in their wide variation and was used to model asphalt concrete [13].

Ground (powder) clay was taken as a binder, and sand was used as filler. The oil, which is part of the proposed equivalent material, simulated the liquid phase that is part of the solid soil and the viscous-plastic properties of asphalt concrete. The evaporation of technical oil is significantly less than that of water, which made it possible to obtain an artificial mixture, the viscosity and physical and mechanical properties of which did not change for a long time. This allows the artificial material to be reused in subsequent tests. The plastic properties of the material were changed by the addition of oil. The lower the percentage of oil corresponds to the manifestation of the brittle properties of the material, the greater the plastic.

The method for preparing an equivalent material includes operations for preparing and controlling the properties of the resulting mixture.

The viscoplastic properties and the similarity of the equivalent material were monitored by three parameters $\sigma_{\mathrm{cs}}, \sigma_{\mathrm{p}}, \mathrm{C}_{\mathrm{sp}}$, and the ratios $\sigma_{\mathrm{cs}} / \sigma_{\mathrm{p}}, \mathrm{C}_{\mathrm{sp}} / \sigma_{\mathrm{p}}$. The $\mathrm{C} s p$ indicator is considered as generalizing.

The control and measuring equipment consisted of a dynamic density meter D-51 for measuring Csp following GOST 30067-093 (Appendix A) and power devices for testing samples for compression and rupture following GOST 21153.3-85.

To determine the tensile strength of the mixture from an array of equivalent material, bars of $0.04 \times 0.04 \times 0.1 \mathrm{~m}$ were cut out and subjected to splitting. The $\sigma_{\mathrm{p}}$ values were determined by the formula:

$$
\sigma_{P}=\frac{2 \cdot P_{\max }}{\pi \cdot \alpha^{2}}
$$

Where $P_{\max }$ is the maximum gain at the moment of rupture;

$\alpha^{2}$ is cross-sectional area of the sample

Samples obtained after splitting were used for compression tests. Cubes measuring $0.04 \times 0.04 \times 0.04 \mathrm{~m}$ were made from them, which were destroyed. The value of $\sigma_{\mathrm{cs}}$ is determined by the formula:

$$
\sigma_{\mathrm{cs}}=\frac{P_{\operatorname{max.cs} .}}{\alpha^{2}}
$$

The relative error in measuring the stresses was determined from the dependence

$$
\varepsilon_{\sigma}<\varepsilon_{p}+2 \cdot \varepsilon_{\alpha} \approx \frac{30}{P_{\max }}+1
$$

Where $\varepsilon_{\sigma}, \varepsilon_{p}$ is the relative measurement error of the force $P_{\max }$ and size $\alpha$, respectively.

The similarity of the equivalent material was established based on a comparison of the experimental values of parameters and quantities with the corresponding data for a fullscale material [2].

The average value of the desired random variable was calculated for the series $n_{l}$ of the current values of the measured values $x_{i}$ by the formula:

$$
\bar{x}=\frac{1}{n_{1}} \cdot \sum_{i=1}^{n} x_{i}
$$

The coefficient of variation of the measured values was determined by the formula: 


$$
K_{\text {var }}=\frac{\sqrt{\frac{1}{n-1} \Sigma\left(x_{i}-\bar{x}\right)^{2}}}{\bar{x}}
$$

The plastic properties of the material depend on the percentage of oil in it. As the oil content increases, the strength of the material decreases. The strength properties of the material depend on the degree of compaction (the number of sealing strokes). When compaction of the mixture, the specific energy of a single impact should be at least 2.2 $\mathrm{J} / \mathrm{sm}^{2}$.

An equivalent material for modeling asphalt concrete was prepared according to the following technology: dry components of the mixture (sand and clay) were dried and sieved; the clay was crushed to a fraction of no more than $0.2 \mathrm{~mm}$; the components were prepared in a proportion of $8 \%$ oil, $40 \%$ clay, $52 \%$ sand; the components were mixed until a homogeneous mixture was obtained; the mixture was placed in a container and compacted under the impact of an impact load. When the mixture was compacted, the specific energy of the compacting impact was not less than 2.2-2.6 J/s $\mathrm{s}^{2}$.

The material retains its composition and properties for a long time and can be reused.

The simulation based on this equivalent material was carried out in the following sequence. According to the material's properties for the original, its dimensionless characteristics $\sigma_{\mathrm{cs}} / \sigma_{\mathrm{p}}$ was determined. The artificial mixture should have the same characteristics. The $S_{\mathrm{db} . n}$ the index was determined by the generalized strength index $S_{\mathrm{db} . n}$ and the scale factor $k_{l} S_{\mathrm{db} . \mathrm{m}}=S_{\mathrm{db} . \mathrm{m}} / k_{l}$. Based on the strength index $\mathrm{k}$ and the dimensionless characteristics $\sigma_{\mathrm{cs}} / \sigma_{\mathrm{p}}$ and $S_{\mathrm{db}} / \sigma_{\mathrm{p}}$, the corresponding characteristics of the equivalent were selected.

According to the recommendation discussed above, the percentage of the components of the mixture and the number of compaction impacts $P_{\mathrm{db}}$ required to compact the mixture to obtain the specified strength $S_{\mathrm{db} . \mathrm{m}}$ were determined. Additionally, the obtained material properties were monitored according to the generalized strength index $S_{\mathrm{db} . \mathrm{m}}$.

So, for the preparation of a material equivalent to asphalt concrete with strength characteristics $\sigma_{c s}=6 \mathrm{MPa}, \sigma_{p}=1,7 \mathrm{MPa}, S_{\mathrm{db} . \mathrm{n}}=120, \sigma_{c s} / \sigma_{p}=3.5, S_{\mathrm{db} . \mathrm{n}} / \sigma_{p}=71 \mathrm{MPa}^{-1}$, the value $k_{l}=10$ was set. The strength of the equivalent material was determined by the number of impacts of the density meter: $S_{\mathrm{db} . \mathrm{m}}=S_{\mathrm{db} . \mathrm{n}} / \mathrm{k}_{l}=120 / 10=12$. Then, by varying the number of compaction impacts $n_{s p}$, the parameters $\frac{\sigma_{c s}}{\sigma_{p}}$ and $\sigma_{s p} / \sigma_{p}$ were determined as close as possible to the analogous parameters of the full-scale material. Close values of the parameters $\sigma_{s p} / \sigma_{p}$ and $\mathrm{S}_{\mathrm{db}} / \sigma_{p}$ were obtained with six compaction impacts and amounted to $\sigma_{s p} / \sigma_{p}=2.9$ and $\mathrm{S}_{\mathrm{db}} / \sigma_{p}=73 \mathrm{MPa}^{-1}$. The last operation was to control the strength according to the generalizing indicator $\mathrm{S}_{\mathrm{db}}$, which should have been $\mathrm{S}_{\mathrm{db}}=12$.

The considered artificial material is cheap and based on available and non-scarce components. This ensures the consistency of material properties for a long time. This allows it to be reused many times for repeated tests. By changing the number of compaction impacts or adding a mixture of other components in the required mass fractions, new materials with different strength characteristics are obtained. This increases the functionality of the model, reduces the consumption of mixture components in the preparation of artificial materials with new properties, and reduces labor and energy costs for experimental research.

\section{Results and Discussion}

1. In the process of experimental research, it is required to find out the effect on the value of the average torque and wear of cutters, the following characteristics of the process of milling asphalt concrete: 
- maximum milling depth;

- translational speed of movement of the road milling cutter.

2. In experimental studies, it is advisable to use an equivalent material consisting of sand, clay, technical oil that meets the similarity criteria.

\section{Conclusions}

The main meaning and goal of our scientific work and article is to reduce the wear of road milling cutters using ion-plasma spraying of the coating and increase the service term.

When conducting research at the Navoi Machine-Building Plant, before our research, the maximum hardness of the material R6M5 or R18 should be up to HRC-65 when measuring the hardness of road mills using a Vickers device. Focusing on the postexperimental situation and the result, the main goal was achieved by increasing the rigidity of the road milling machines by $25 \%$.

\section{References}

1. J.Xiang, X.Zhu, G.Chen, Z.Duan, Yan Lin, Ying Lin. Oxidation behavior of Fe40Al$x W C$ composite coatings obtained by high-velocity oxygen fuel thermal spray, Trans. Nonferrous Met. Soc, 19, pp.1545-1550, China, (2009)

2. H.-T.Wang, Ch-J.Li, G.-J.Yang, Ch-X.Li. Effect of Heat Treatment on the Microstructure and Property of Cold-Sprayed Nanostructured FeAl /Al2O3 Intermetallic Coating, 83, pp. 146-152 (2009)

3. N.Cinca, J.M. Guilemany. Thermal spraying of transition metal aluminides, An overview: Intermetallics, 24, pp. 60-72, (2012)

4. Tulkun Ishanovich Askarxodjayev, Sharofiddin Asatullayevich Pirnayev Research of The Processes of Wering the Working Bodies of Road Mills International Journal of Psychological Rehabilitation, Vol.24. Issue 07.2020 Issn:1475-7192 Scope. Pp.80528062 (2020)

5. Senderowski C., Bojar Z., Roy G., Czujko T., Wolczynski W. Residual Stresses Determined by the Modified Sachs Method Within a Gas Detonation Sprayed Coatings of the Fe-Al Intermetallic, Archives of Metallurgy and Materials, 52(4), p.10, (2007)

6. Kumar S., Selvarajan V., Padmanabhan P.V., Sreekumar K.P. Characterization and comparison between ball milled and plasma processed iron-aluminium thermal spray coatings, Surface and Coatings Technology, 201, pp. 1267-1275, (2006)

7. Wang H.T., Ch-J.Li, G.-J.Yang, Ch-X.Li. Cold Spraying of Fe/Al Powder mixture: Coating Characteristic and Influence of Heat Treatment on the Phase Structure, Applied Surface Science, 255, pp. 2538-2544 (2008)

8. Sanjeev Chandra, Pierre Fauchais. Formation of Solid Splats During Thermal Spray Deposition, Journal of Thermal Spray Technology, 18 (2), pp. 148-180 (2009)

9. Krasnoludkiy A.V. Determination of rational parameters of an eccentric road milling machine, Saratov, SSU, pp. 177, (2004)

10. Kostelov M.V. Milling technologies for the repair and strengthening of road surfaces, Construction and real estate, № 7, pp. 28-30, (2001)

11. Popov S.N., Antonyuk D.A. Analysis of the nature of wear and determination of performance criteria for the working bodies of road milling cutters, Problems of tribology, № 1, pp. 3-12, (2007) 
12. Gavrilin A.N., Moises B.B., Chervach Y.B., Rubtsov V.L., Borisov K.I., Melnov K.V., Khairullin A.R. Research methodology of rock characteristics during cutting and chipping with PDC cutters, POLZUNOVSKY VESTNIK № 4, pp. 80-83, (2016)

13. Borisov K.I. Scientific method for assessing the effectiveness of dynamic processes of destruction of rocks when drilling wells with modern tools of cutting and shearing action, p. 193, Tomsk, (2012)

14. Neskoromnykh V.V. Analytical study of the temporary strength characteristics of a rock during cutting-chipping with PDC cutters, Proceedings of TPU, 235(1), pp. 172178, (2014)

15. Popov V.S., Lunyak V.L. Installation for testing surfacing materials during abrasive wear, Zavodskaya laboratory Metallurgy, 40(2), pp. 231-232 (1974)

16. Gaidyshev I. Analysis and data processing, Special reference book, Saint-Petersburg, p. 750, (2001)

17. GOST R 50779.21-2004 Statistical methods, Definition rules and methods for calculating statistical characteristics based on sample data

18. S. D. Ignatov, N. S. Sherstnev. Analysis of the mathematical model of the working process of a road cutter during the destruction of asphalt concrete. SibADI, Omsk, Russia. SibADI Bulletin, issue 3 (55), 2017. - c. 120-124.

19. Talerov, M.P. Increasing the efficiency of using rotary cutters of roadheaders by choosing rational geometric parameters of tools: dis. ... Cand. tech. Sciences: 05.05.06 / Talerov Mikhail Pavlovich. - SPb., 2012 .-- 147 p.

20. Fomin K.V. Modeling and calculation of the probabilistic characteristics of the moment of resistance on the working body of the road milling machine. Scientific and Technical Bulletin of Bryansk State University, 2019, No. 3. pp. 407-417.

21. Demidenko A.I., Snigerev D.S., Vaymer E.Yu., Sushko A.G. Laboratory tests of the knives of the soil milling cutter. Transport and technological machines. Bulletin of SibADI, issue 3 (17), 2010. - pp. 5-8.

22. Lukash V.A., Virovets L.M., Melnichuk O.V. Analysis of the progress and the direction of the progress of the road studies // In collection. Abstracts VI Conf. "The effectiveness of the implementation of scientific, resource and industrial potential in modern conditions." - pp. 320-322.

23. Seliverstov, N.D. Influence of operating modes of road milling cutters and wear of cutting elements on the profile of the surface being formed. Seliverstov // Interstroymekh-2014: Materials of the Intern. scientific and technical. Conf., 2014. pp. 77-81.

24. Krasnoludkiy A.V. Determination of rational parameters of an eccentric road milling machine: Dis. ... Cand. tech. sciences. - Saratov, SSU, 2004. - 177 p.

25. Kostelov M.V. Milling technologies for the repair and strengthening of road surfaces // Construction and real estate, 2001. -№7 - pp. 28-30. 